\title{
APLICAÇÃO DE ZEÓLITAS SINTÉTICAS COMO COADJUVANTE EM FORMULAÇÃO DETERGENTE
}

Felipe K. Sutili, Naiara Miotto, Eduardo Rigoti, Sibele B. C. Pergher e Fábio G. Penha*

Departamento de Química, Universidade Regional Integrada do Alto Uruguai e das Missões, Campus Erechim, Av. Sete de Setembro, 1621, 99700-000 Erechim - RS, Brasil

Recebido em 20/3/08; aceito em 23/10/08; publicado na web em 6/3/09

\begin{abstract}
APPLICATION OF SYNTHETIC ZEOLITES AS BUILDER IN DETERGENT FORMULATION. The study consists is the application of zeolites $\mathrm{NaX}, \mathrm{NaY}$ and $\mathrm{A}$ as builder in detergent formulations to eliminate the hardness of water. Therefore, the adsorption of ions $\mathrm{Ca}^{+2}$ and $\mathrm{Mg}^{+2}$ were evaluated, and the effect of the cleaning action of the surfactant sodium dodecil sulfate (SDS) through tests of detergency. The experiments were conducted in bath system (with shaking) and quantification of metals was

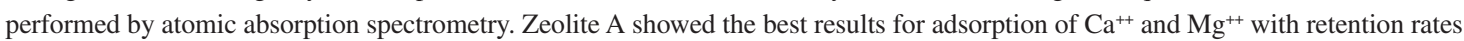
of around 90 and $70 \%$ respectively and acted positively on the action of cleaning the surfactant SDS.
\end{abstract}

Keywords: zeolite; builder; detergent.

\section{INTRODUÇÃOO}

Surfactantes ou tensoativos são compostos que apresentam em sua estrutura um grupo apolar constituído de cadeias carbônicas longas com um grupo catiônico ou aniônico ou polar em sua extremidade. Estes compostos são os principais componentes dos detergentes, que devido ao seu poder anfifílico podem remover sujidades que a água não removeria sozinha. ${ }^{1,2}$

A água de lavagem tem grande influência sobre a eficácia dos detergentes. As águas duras contêm metais, principalmente cálcio $\left(\mathrm{Ca}^{+2}\right)$ e magnésio $\left(\mathrm{Mg}^{+2}\right)$ que formam precipitados com os tensoativos dos detergentes. Em meio ácido, o processo de limpeza de um tensoativo aniônico também é prejudicado pela formação de ácido graxo, insolúvel em água. Para complexar esses íons metálicos e desacidificar o meio são adicionados fosfatos inorgânicos condensados. Estas substâncias são agentes seqüestrantes responsáveis pelo aumento da estabilidade dos sistemas onde são empregados. ${ }^{3,4}$

Os fosfatos promovem a alcalinidade e são excelentes abrandadores de águas duras, porém causam sérios problemas ao meio ambiente, não pela sua toxicidade, mas sim pela nutrição excessiva para sistemas aquáticos. Isso resulta na eutrofização, definida como um crescimento exagerado no número de algas e formas superiores de plantas aquáticas, ocasionando um desequilíbrio biológico no meio. ${ }^{3}$

Com o aval de ambientalistas alguns países da União Européia como Bélgica, Alemanha, Itália, Irlanda e Áustria introduziram legislações restringindo a adição dos fosfatos nos detergentes para roupas. As zeólitas, aluminossilicatos de alta porosidade, tornam-se um substituto conveniente para tal propósito, pois possuem uma alta capacidade de troca catiônica. ${ }^{3,5-10}$

Neste sentido, o trabalho teve como objetivo a substituição de polifosfatos das formulações detergentes para limpeza doméstica e/ou industrial por zeólitas sintéticas. A influência da zeólita na atuação de limpeza do surfactante, bem como a avaliação da adsorção zeolítica frente ao tensoativo SDS (dodecilsulfato de sódio) e o efeito do $\mathrm{pH}$ também foram estudados.

\section{PARTE EXPERIMENTAL}

\section{Equipamentos e métodos}

Soluções de $\mathrm{Ca}^{+2} \mathrm{e} \mathrm{Mg}^{+2}$ foram preparadas separadamente, simulando uma dureza de água elevada, ou seja, com uma concentração destes íons maior que $150 \mathrm{ppm}$. As concentrações destes cátions foram determinadas por um espectrômetro de absorção atômica (AAS), Varian, modelo 550 (comprimento de onda de 422,7 nm para $\mathrm{Ca}^{+2}$ e 202,6 nm para $\mathrm{Mg}^{+2}$ ), com chama de ar/acetileno como fonte de energia e respectiva lâmpada de cátodo oco para cada elemento. O estudo de adsorção e o teste de detergência foram realizados através de um shaker.

Como adsorvente foram empregadas zeólitas comerciais: $\mathrm{NaX}$ Baylight WE894 da Bayer com relação molar Si/Al = 1,49 e $\mathrm{A}_{\mathrm{BET}}=$ $332,2 \mathrm{~m}^{2} / \mathrm{g}$, zeólita NaY CBV100 com relação molar $\mathrm{Si} / \mathrm{Al}=5,2$ e $\mathrm{A}_{\mathrm{BET}}=654 \mathrm{~m}^{2} / \mathrm{g}$ e zeólita $\mathrm{A}$ sintetizada ${ }^{11}$ com relação molar $\mathrm{Si} / \mathrm{Al}=$ 1 e $\mathrm{A}_{\mathrm{BET}}$ na forma $\mathrm{Ca}^{+2}=495 \mathrm{~m}^{2} / \mathrm{g}$.

A caracterização das zeólitas foi realizada por difração de raioX (Difractometer-D5000, Siemens). Todas as soluções utilizadas no estudo foram preparadas com reagentes de grau analítico e água deionizada Milli-Q.

\section{Estudos de adsorção}

O estudo de adsorção das diferentes zeólitas foi realizado em sistema batelada. Para isso, foi utilizado o shaker a $133 \mathrm{rpm}$ como processo descontínuo sob agitação. Alíquotas de $20 \mathrm{~mL}$ das soluções de cloreto de cálcio e cloreto de magnésio de concentração fixa (500 $\mathrm{mg} / \mathrm{L}$ ) foram colocadas em contato com $100 \mathrm{mg}$ de zeólita $\mathrm{NaX}, \mathrm{NaY}$ ou A. O efeito do $\mathrm{pH}$ na adsorção foi testado a temperatura de $40{ }^{\circ} \mathrm{C}$ e ajustado a pH 5, 7 ou 9. O tempo de contato foi de 1, 12 e $24 \mathrm{~h}$ e o sobrenadante foi analisado por espectrômetro de absorção atômica para determinação da concentração do íon metálico. Da mesma forma, soluções de surfactante dodecil sulfato de sódio $\mathrm{C}_{12} \mathrm{H}_{25} \mathrm{NaO}_{4} \mathrm{~S}$ (SDS) com concentrações de 50, 100, 150, 200 e $250 \mathrm{mg} / \mathrm{L}$ foram postas em contato com a água dura e a zeólita de maior adsorção para avaliação da influência do tensoativo frente à adsorção da zeólita. 


\section{Teste de detergência}

A análise dos efeitos entre a zeólita e o poder de limpeza do surfactante foi realizada perante teste de lavado. Aderiu-se através de aquecimento a sujidade (ácido esteárico, $\mathrm{pf}=70^{\circ} \mathrm{C}$ ) na superfície do substrato (esferas de vidro de aproximadamente $3 \mathrm{~mm}$ de diâmetro). $\mathrm{O}$ binômio sujidade-substrato foi posto em contato com a água dura, o surfactante e a zeólita de maior adsorção, e mantido por 5 min sob constante agitação a temperatura de $20^{\circ} \mathrm{C}$. A eficiência na remoção da sujidade foi obtida através do índice de acidez ${ }^{12}$ realizado por método titulométrico com $\mathrm{KOH}$ etanólico $(0,1 \mathrm{~mol} / \mathrm{L})$. A partir do volume de $\mathrm{KOH}$ gasto para neutralizar o ácido contido na amostra se pode, através de uma reta padrão, conhecer a quantidade de sujidade removida e calcular a detergência.

\section{RESULTADOS E DISCUSSÃO}

\section{Análise dos adsorventes}

Os difratogramas de raios-X das zeólitas estudadas estão ilustrados na Figura 1. Os difratogramas das zeólitas A e NaY quando comparados com a literatura ${ }^{13}$ confirmam as estruturas das zeólitas com alto grau de cristalinidade.

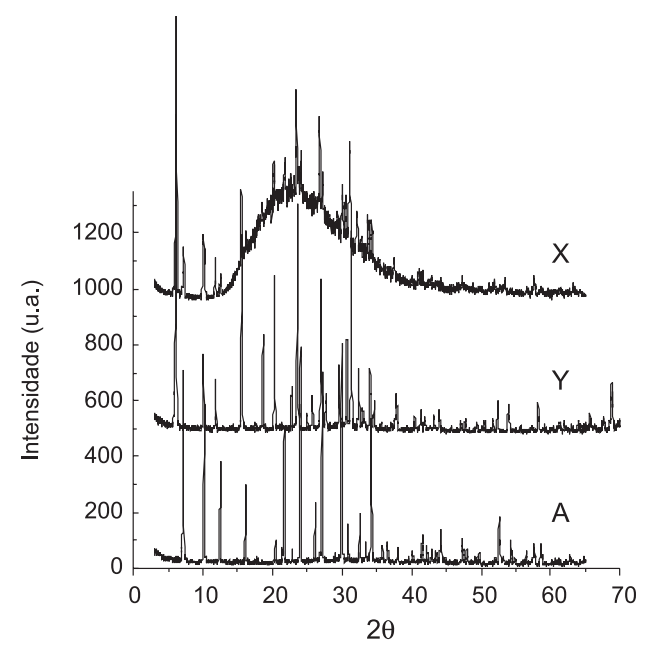

Figura 1. Difratogramas de raios- $X$ das zeólitas estudadas

As zeólitas X e Y possuem a mesma estrutura faujasita oriunda da união de caixas sodalita. ${ }^{14}$ Diferem apenas na relação intrarreticular de Si/Al. Por isso, possuem picos semelhantes em seus difratogramas. Porém a zeólita $\mathrm{NaX}$ possui uma banda larga na região de 15 a $35^{\circ}$, indício de uma fase amorfa oriunda de sua síntese ou de algum aditivo utilizado para confecção das esferas (forma em que é comercializada). Também apresenta picos de outra fase zeolítica (A), demonstrando seu baixo grau de pureza.

\section{Efeito do tipo de zeólita}

A taxa de íons metálicos adsorvidos (\%) foi calculada através do decréscimo da concentração de íons metálicos no meio:

Taxa de íons adsorvidos $=\left[\left(\mathrm{C}_{\mathrm{o}}-\mathrm{C}\right) / \mathrm{C}_{\mathrm{o}}\right] \times 100$

onde $\mathrm{C}_{\mathrm{o}}$ e $\mathrm{C}$ são, respectivamente, as concentrações da fase aquosa antes e depois do período de tratamento com a zeólita $(\mathrm{mg} / \mathrm{L})$.

A Figura 2 mostra os resultados obtidos após 1,12 e 24 h de agitação a $40{ }^{\circ} \mathrm{C}$ para os íons de $\mathrm{Ca}^{+2} \mathrm{e} \mathrm{Mg}^{+2}$ a $\mathrm{pH} 7$ para as zeólitas avaliadas.

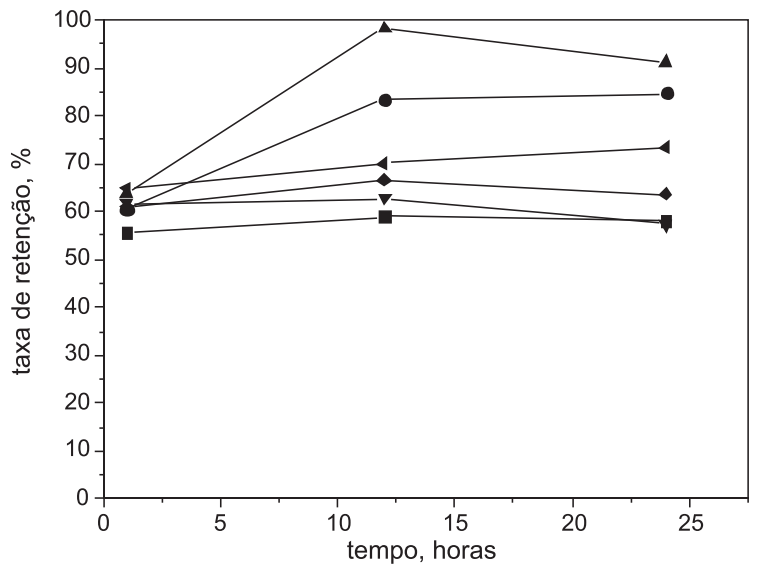

Figura 2. Retenção de íons $\mathrm{Ca}^{+2}$ e $\mathrm{Mg}^{+2}$ para cada $100 \mathrm{mg}$ das zeólitas avaliadas em 1, 12 e 24 ha $40{ }^{\circ} \mathrm{C}, \mathrm{pH} \mathrm{7,} \mathrm{com} \mathrm{concentração} \mathrm{inicial} \mathrm{de} 500$ mg/L para ambos os metais: - $\mathrm{NaY}-\mathrm{Ca}^{+2}$; $\mathrm{NaX}-\mathrm{Ca}^{+2} ; \mathbf{\Delta} \mathrm{A}-\mathrm{Ca}^{+2}$; $\nabla \mathrm{NaY}-\mathrm{Mg}^{+2} ; \nabla \mathrm{NaX}-\mathrm{Mg}^{+2} ; \backslash \mathrm{A}-\mathrm{Mg}^{+2}$

Observa-se que a zeólita A adsorve quantidades superiores de íons de $\mathrm{Ca}^{+2} \mathrm{e} \mathrm{Mg}^{+2}$ nos três tempos estudados, praticamente chegando à saturação em 12 h, com uma taxa de retenção em torno de 98 e 70\%, respectivamente. As zeólitas $\mathrm{NaX}$ e $\mathrm{NaY}$ apresentam 83 e $59 \%$ de retenção, respectivamente, para íons de $\mathrm{Ca}^{+2}$ e 66 e $62 \%$ para $\mathrm{Mg}^{+2}$, no mesmo intervalo de tempo.

As zeólitas A, $\mathrm{NaX}$ e $\mathrm{NaY}$ não terão problemas de acessibilidade dos seus sítios ativos; o que governará o processo é a relação $\mathrm{Si} /$ Al. Neste caso, as zeólitas A e NaX levam vantagem, pois possuem relação $\mathrm{Si} / \mathrm{Al}$ próximas a 1 . Mas, sabe-se que a adsorção da zeólita NaX é prejudicada pelo material amorfo presente em sua constituição, pois não possui propriedades adsorventes. ${ }^{14}$

A relação reticular de $\mathrm{Si} / \mathrm{Al}$ é, portanto, o fator determinante para a maior adsorção da zeólita $\mathrm{A}$, pois o $\mathrm{Al}$ confere uma densidade de carga negativa sobre o oxigênio ligado, assim, há a necessidade de cátions compensadores para a neutralidade elétrica, que poderão ser posteriormente trocados. Portanto, uma baixa relação $\mathrm{Si} / \mathrm{Al}$ resulta em uma maior capacidade de troca catiônica. ${ }^{14}$

A Figura 2 também mostra uma menor taxa de retenção de $\mathrm{Mg}^{+2}$ em comparação ao $\mathrm{Ca}^{+2}$, provavelmente devido a sua elevada energia de hidratação. ${ }^{15}$

\section{Efeito do pH}

Considerando a aplicabilidade da zeólita na formulação detergente foi avaliado o efeito do $\mathrm{pH}$ na adsorção das zeólitas estudadas. Os resultados são mostrados na Figura 3 para o $\mathrm{Ca}^{+2}$ e para o $\mathrm{Mg}^{+2}$.

O estudo do $\mathrm{pH}$ na capacidade de retenção da zeólita é importante, pois, dependendo do tipo da sujidade a ser limpa, pode-se gerar um caráter ácido ou básico no meio. O caráter dos cátions trocáveis bem como o da própria zeólita é afetado pelo $\mathrm{pH}$, pois baixos valores de $\mathrm{pH}$ correspondem à maior concentração de íons $\mathrm{H}^{+}$livres em solução. Quanto mais ácida for a solução, maior será a competição entre os íons $\mathrm{H}^{+}$e os de metais para serem adsorvidos, o que dificulta a adsorção destes. Isso pode ser observado nas adsorções em pH 5, que resultaram em menores taxas de retenção. Um pH baixo pode ainda acarretar a degradação da estrutura zeolítica com correspondente perda de alumínio. ${ }^{14}$

Sabe-se ainda que um $\mathrm{pH}$ ácido pode interferir não só na estrutura da zeólita, mas também na ação da matéria ativa de alguns detergentes, precipitando um tensoativo aniônico. Em contrapartida, um meio alcalino também pode afetar a detergência de um tensoativo catiônico, portanto, deve-se preferir $\mathrm{pH}$ neutro para a melhor atuação do surfactante. 


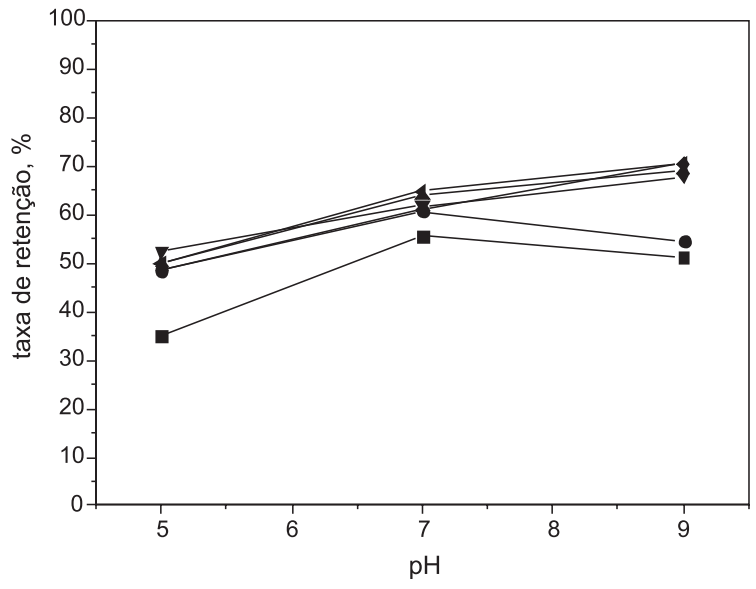

Figura 3. Retenção de íons $\mathrm{Ca}^{+2}$ e $\mathrm{Mg}^{+2}$ para cada $100 \mathrm{mg}$ das zeólitas avaliadas em pH 5, 7 e 9 a $40{ }^{\circ} \mathrm{C}$ em $1 \mathrm{~h}$ de agitação com concentração inicial de $500 \mathrm{mg} / \mathrm{L}$ para ambos os metais: $\mathrm{NaY}-\mathrm{Ca}^{+2}$; $\mathrm{NaX}-\mathrm{Ca}^{+2}$; $\Delta \mathrm{A}-\mathrm{Ca}^{+2} ; \nabla \mathrm{NaY}-\mathrm{Mg}^{+2} ; \diamond \mathrm{NaX}-\mathrm{Mg}^{+2} ;\left\langle\mathrm{A}-\mathrm{Mg}^{+2}\right.$

Com o aumento do $\mathrm{pH}$, também se tem maior concentração de complexos formados por outros ligantes inorgânicos, como $\mathrm{OH}^{-}$. Estas estruturas, além de serem maiores, podem afetar a solubilidade do metal em questão, dificultando o processo de troca iônica. ${ }^{16}$ Tal fato pode ser mais bem evidenciado na adsorção de $\mathrm{Mg}^{+2}$, onde a adsorção é favorecida a pHs elevados ( 9). Entretanto, não se descarta a hipótese de que pode estar ocorrendo a eliminação de $\mathrm{Mg}^{+2}$ via precipitação na forma de hidróxido, visto que seu $\mathrm{pH}$ de precipitação vai de 8 a 12,5, dependendo da concentração. Isso não ocorre com o $\mathrm{Ca}^{+2}$, pois sua precipitação só ocorre a partir de $\mathrm{pH} 11$.

\section{Efeito do tensoativo SDS na adsorção}

A avaliação da capacidade de adsorção frente ao tensoativo SDS foi realizada empregando a zeólita A, visto que em qualquer faixa de $\mathrm{pH}$ possui as maiores taxas de retenção e que sua variação na adsorção de $1 \mathrm{~h}$ nesses pHs não é tão acentuada.

Testes de adsorção empregando as zeólitas $\mathrm{NaX}$ e NaY também foram realizados e verificou-se um aumento na taxa de retenção com o uso do surfactante. Entretanto, como os resultados alcançados com a zeólita A foram mais promissores, somente estes serão apresentados.

Para avaliar a influência do tensoativo na adsorção, empregouse como cátion modelo o $\mathrm{Ca}^{+2}$, uma vez que este apresentou maior capacidade de troca catiônica na zeólita.

A Figura 4 mostra os resultados das adsorções para o $\mathrm{Ca}^{+2}$, empregando-se a zeólita A nas diferentes concentrações de surfactante em pH 5, 7 e 9.

Comparando as Figuras 3 e 4, sem e com SDS respectivamente, observa-se que a taxa de retenção dos íons sobre a zeólita aumenta significativamente na presença do surfactante. Independente da concentração do SDS, o aumento da taxa de retenção na zeólita avaliada é de 10 a $20 \%$ maior para os íons $\mathrm{Ca}^{+2}$. Sendo assim, a zeólita pode ser usada como abrandador de águas duras com satisfatória eliminação de íons $\mathrm{Ca}^{+2}$.

\section{Cinética em tempos inferiores a $1 \mathrm{~h}$}

Em qualquer faixa de $\mathrm{pH}$ e concentração de surfactante percebese que a zeólita A possui altas taxas de retenção. Em virtude disso, optou-se por empregar a zeólita A como coadjuvante na formulação detergente no abrandamento da dureza da água.

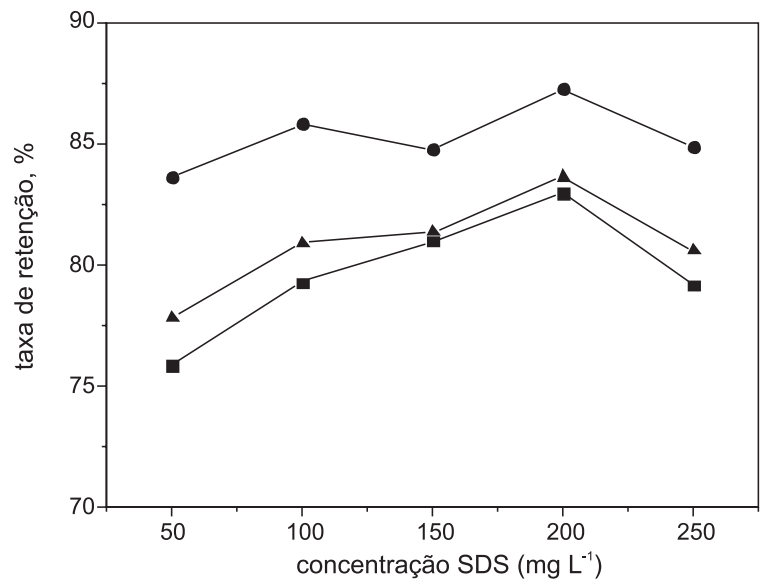

Figura 4. Retenção de íons $\mathrm{Ca}^{+2}$ com concentração inicial de $500 \mathrm{mg} / \mathrm{L}$ para cada $100 \mathrm{mg}$ de zeólita A, frente a variadas concentrações de surfactante $S D S(\mathrm{mg} / \mathrm{L})$ a $40{ }^{\circ} \mathrm{Cem} \mathrm{pH} \mathrm{5,} 7 \mathrm{e} 9 \mathrm{em} 1 \mathrm{~h}$ de agitação: $\mathrm{aH}=5,00$; - $p H=7,00 ; \mathbf{\Delta} p H=9,00$

Em função do exposto, foi realizada outra série de experimentos para avaliar o comportamento adsortivo da zeólita A em tempos inferiores a $1 \mathrm{~h}$. A cinética foi realizada em $\mathrm{pH} 7$ devido à aplicabilidade comercial dos detergentes em não oferecer qualquer tipo de risco à saúde dos usuários, mas sabe-se, como já discutido anteriormente, que seu meio reacional assume outros caracteres dependendo das sujidades a serem limpas. Os resultados da adsorção estão ilustrados na Figura 5.

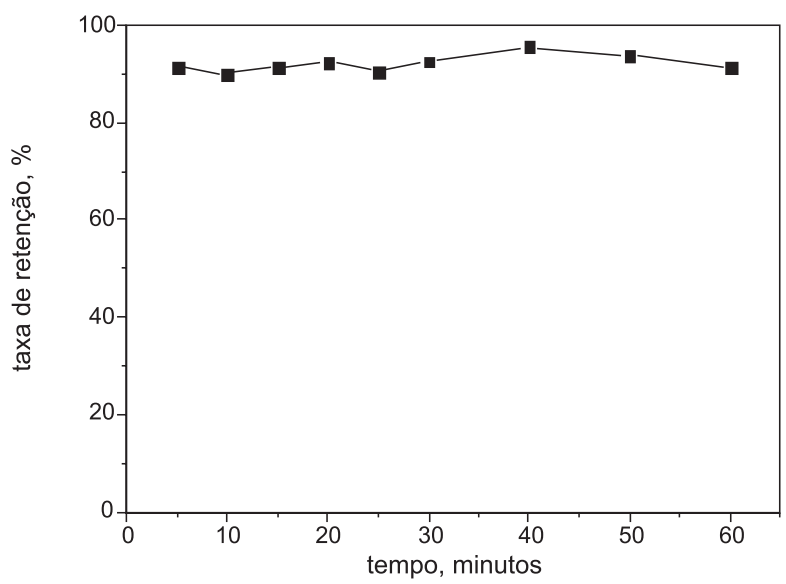

Figura 5. Retenção de íons $\mathrm{Ca}^{+2}$ com concentração inicial de $250 \mathrm{mg} / \mathrm{L}$ para cada $100 \mathrm{mg}$ da zeólita A e com $200 \mathrm{mg} / \mathrm{L}$ de surfactante em $\mathrm{pH}$ 7, a $40^{\circ} \mathrm{C}$

Observa-se que em 5 min a retenção foi de $90 \%$ para $\mathrm{Ca}^{+2}$, ficando praticamente constante. Isto significa que em 5 min o equilíbrio foi atingido, mostrando que o íon $\mathrm{Ca}^{+2}$ possui elevada afinidade pela zeólita.

\section{Efeito da zeólita na detergência do SDS}

O teste de detergência é importante no desenvolvimento de uma formulação detergente, pois determina a eficiência da matéria ativa e dos coadjuvantes nas dadas condições de trabalho. São ensaios de laboratório que se baseiam em avaliações gravimétricas, visuais ou espectrofotométricas ${ }^{17}$ que irão determinar as concentrações ideais dos compostos da formulação do detergente, e como eles intervêm na detergência. 
Os dispositivos e procedimentos de lavado disponíveis para a avaliação da detergência em tecidos são muito mais numerosos que os utilizados para superfícies duras. ${ }^{17}$ Alguns dos ensaios para limpeza de superfícies duras que se baseiam em avaliações visuais se diferenciam apenas na mecânica de imersão das superfícies a serem limpas.

Devido ao baixo número de testes de detergência normalizados e a rusticidade de alguns métodos, muitos pesquisadores ${ }^{17}$ se detêm a desenvolver novos ensaios com esta finalidade. Baseado nisso foi desenvolvido um sistema de avaliação em batelada com a finalidade de avaliar o efeito da zeólita na detergência do SDS.

A Figura 6 mostra a reta padrão para o ácido esteárico que relaciona o volume de $\mathrm{KOH}$ gasto para neutralizar a massa de ácido. Nesta figura observa-se que os pontos experimentais se ajustam perfeitamente a uma reta $\left(r^{2}=0,9995\right)$, indicando que as condições ensaiadas, às diferentes concentrações de ácido esteárico não influenciam na determinação do índice de acidez, validando o método.

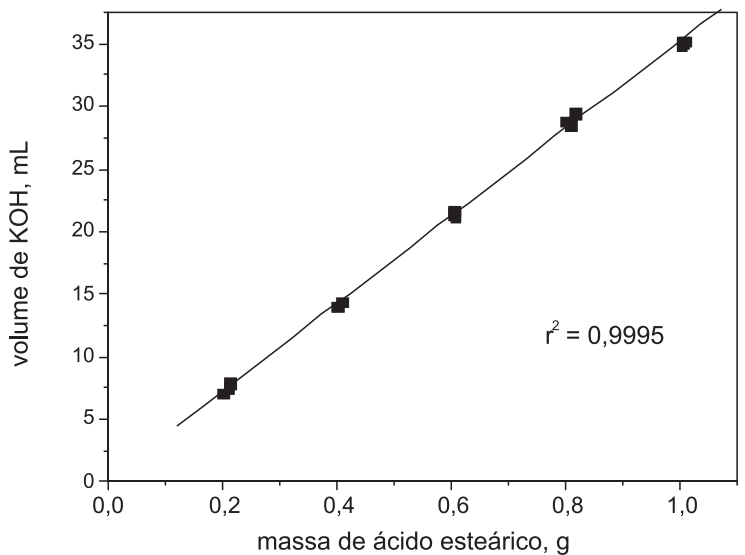

Figura 6. Relação entre a massa de ácido esteárico e o volume de $\mathrm{KOH}(0,1$ mol/L) gasto na titulação da amostra

A detergência foi calculada através da relação percentual entre a massa de sujidade retirada da superfície do substrato depois da lavagem e a massa de sujidade presente no substrato (esferas de vidro):

$\operatorname{De}(\%)=\mathrm{Fv} \times\left(\mathrm{m}_{\text {amostra }} / \mathrm{m}_{\text {inicial }}\right)_{\mathrm{x}} 100$

onde De (\%) corresponde à eficácia detersiva (detergência); Fv é o fator de correção entre os volumes da amostra e do sistema; $\mathrm{m}_{\text {amostra' }}$, a massa de sujidade presente na amostra e $m_{\text {inicial, }}$ a massa de sujidade impregnada nas esferas de vidro. O fator de correção Fv é a relação entre o volume total do ensaio e o volume da amostra analisada. A Figura 7 ilustra os resultados obtidos após 5 min de agitação a $20^{\circ} \mathrm{C}$.

Observa-se na Figura 7 um aumento na detergência em torno de $3 \%$, evidenciando que a adição da zeólita intervêm de forma positiva na eficácia do surfactante na remoção da sujidade. Isso ocorre devido à adsorção dos íons $\mathrm{Ca}^{+2}$ sobre a zeólita.

A detergência obtida (3\%) é significativa, visto que há uma elevada afinidade da sujidade (ácido esteárico) pelo substrato (esferas de vidro), pois o ácido graxo é solidificado no vidro com grande aderência, dificultando sua retirada. Trabalhou-se nessas condições para verificação do comportamento da zeólita e do tensoativo em situações extremas.

Sabe-se que tal dureza prejudica consideravelmente a atuação do SDS, pois a concentração de íons metálicos é muito superior à quantidade de tensoativo. Em determinadas condições, os metais podem reduzir os potenciais elétricos das partículas de sujeira dispersas no banho de lavado, provocando a floculação e, conseqüentemente, a redeposição das mesmas. ${ }^{17}$

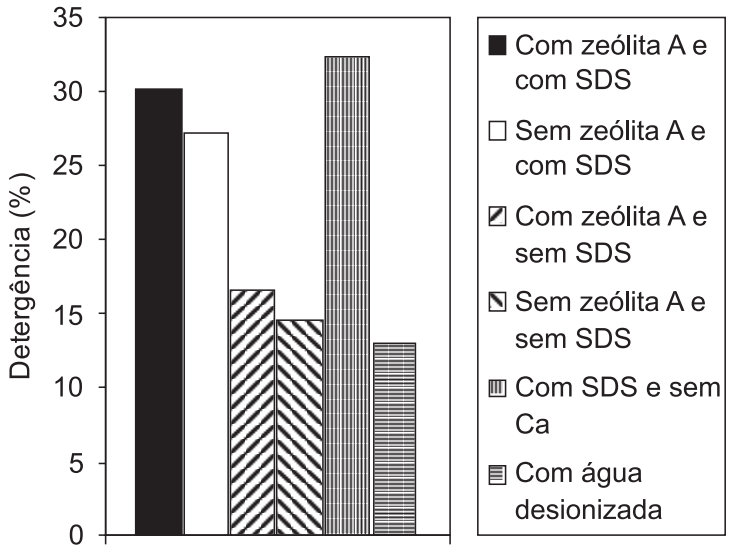

Figura 7. Resultados do teste de detergência empregando $500 \mathrm{mg} / \mathrm{L}$ de $\mathrm{Ca}^{+2}$ e com $200 \mathrm{mg} / \mathrm{L}$ de SDS para $100 \mathrm{mg}$ de zeólita A

A validação dos testes também pode ser verificada quando se comparam os ensaios com e sem surfactante e o ensaio em branco com água deionizada. Observa-se que a detergência aumenta em todos os ensaios com a adição do tensoativo, evidenciando que o fator determinante da limpeza se dá por sua ação detergente e não pela agitação mecânica.

Observa-se também que a zeólita sem a presença de surfactante melhora a detergência, talvez pelo atrito que ela propicia ao meio de lavado, auxiliando na retirada da sujidade.

A concentração de SDS nos ensaios $(0,1-0,5 \mathrm{~g} / \mathrm{L})$ foi utilizada abaixo de sua concentração micelar crítica (CMC), que vai de 2,16 a 2,45 g/L, mas sabe-se que o processo de limpeza seria melhorado se fosse realizado dentro da CMC, pois as melhores condições físico-químicas para uma limpeza eficiente são obtidas nesta faixa. ${ }^{17}$ Poder-se-ia aumentar ainda mais a detergência adicionando mais tensoativo a concentrações superiores à $\mathrm{CMC}$, pois continuaria havendo a solubilização da sujidade graxa no interior das micelas. ${ }^{17}$

\section{CONCLUSÃO}

Das três zeólitas empregadas, a zeólita A foi a que apresentou

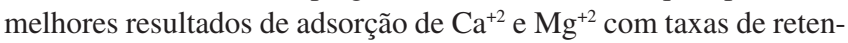
ção em torno de 90 e $70 \%$, respectivamente. Ficou evidente que a elevação do pH aumenta a adsorção das zeólitas, tendo uma influência considerável no processo. O SDS aumenta a retenção de íons $\mathrm{Ca}^{+2}$ não interferindo no processo de adsorção das zeólitas. A zeólita A atua positivamente sobre a ação de limpeza do SDS em se tratando de íons $\mathrm{Ca}^{+2}$, podendo ser usada em formulações detergentes com tal surfactante (SDS) como coadjuvante no abrandamento da dureza da água. Trabalhando-se em condições extremas de sujidade-substrato obteve-se $3 \%$ de melhora na detergência.

O sistema em batelada desenvolvido para avaliar o efeito da zeólita na detergência do surfactante foi satisfatório, cumprindo os objetivos propostos. Os resultados apresentados nos testes foram coerentes com os conceitos teóricos, demonstrando a confiabilidade dos ensaios, podendo ser utilizados na determinação da detergência de surfactantes.

\section{REFERÊNCIAS}

1. Boskamp, J. V.; Houghton, M. P.; Zeolites 1996, 17, 525.

2. Atkins, P. W.; Jones, L. L.; Chemistry - Molecules, Matter and Change, W. H. Freeman and Co.: New York, $3^{\text {rd }}$ ed, 1997.

3. Hui, K. S.; Chao, C. Y. H.; J. Hazard.Mat. 2006, B137, 401.

4. Osorio, V. K. L.; Oliveira, W.; Quim. Nova 2001, 24, 700. 
5. Lucas, A.; Rodríguez, L.; Sánchez, P.; Lobato, J.; Ind. Eng. Chem. Res. 2003, 42, 3257.

6. Adams, J. C.; Araya, A.; Carr, S. W.; Chapple, A. P.; Franklin, K. R.; Grahan, P.; Minihan, A. R.; Osinga, T. J.; Stuart, J. A.; Studies in Surface Sci. Catalysis 1997, 105, 1667.

7. Townsend, R. P.; Studies in Surface Sci. Catalysis 1991, 58, 359.

8. Schwuger, M. J.; Liphard, M.; Studies in Surface Sci. Catalysis 1989, $46,673$.

9. Upadek, H.; Krings, P.; Studies in Surface Sci. Catalysis 1989, 46, 701.

10. http://ec.europa.eu/enterprise/chemicals/legislation/detergents/reports/ com_2007_234_pt.pdf, acessada em Março 2007.
11. Rigo, R. T.; Petkowicz, D. I.; Pergher, S. B. C.; Resumos do $14^{o}$ Congresso Brasileiro de Catálise, Porto de Galinhas, Brasil, 2007.

12. IUPAC - International Union of Pure and Applied Chemistry; Standard Methods for the Analysis of Oils, Fats and Soaps 1964, II. D. 1.

13. Ballmoos, R.Von; Collection of Simulated XRD Powder Patterns for Zeolites, Butterwortth, 1984.

14. Giannetto, G. P.; Zeolitas: Caracteristicas, propriedades y aplicaciones industrials, EdiT - Ediciones Innovación Tecnológica: Caracas, 1990.

15. Petrus, R.; Warchol, J.; Microporous Mesoporous Mater. 2003, 61, 137.

16. Ouki, S. K.; Kavannah, M.; Wat. Sci. Technol. 1999, 39, 115.

17. Vaz, D.A; Tesis Doctoral, Universidad de Granada, Espanha, 2004. 